\title{
Clinical Study \\ Safety Pin Suture for Management of Atonic Postpartum Hemorrhage
}

\author{
Ali Abdelhamed M. Mostfa and Mostafa M. Zaitoun \\ Department of Obstetrics and Gynecology, Faculty of Medicine, Zagazig Universiy, P.O. Box 44519, Sharqia, Egypt \\ Correspondence should be addressed to Ali Abdelhamed M. Mostfa, gyne_doc@yahoo.com
}

Received 26 December 2011; Accepted 26 January 2012

Academic Editors: I. Diez-Itza, D. Schust, and K. Yang

Copyright ( $) 2012$ A. A. M. Mostfa and M. M. Zaitoun. This is an open access article distributed under the Creative Commons Attribution License, which permits unrestricted use, distribution, and reproduction in any medium, provided the original work is properly cited.

Objective. To assess the efficacy of a new suture technique in controlling severe resistant uterine atonic postpartum hemorrhage. Patients and Methods. This is a retrospective observational study that included thirteen women with uterine atony and postpartum bleeding that did not react to usual medical management. All these women underwent compressing vertical suture technique in which the anterior and posterior walls of the uterus were attached so as to compress the uterus. The suture is transfixed at the uterine fundus, thus eliminating the risk of sutures sliding off at the uterine fundus (safety pin suture). Results. safety pin uterine compression suture was a sufficient procedure to stop the bleeding immediately in $92.2 \%$ of the women. None of the women developed complications related to the procedure. Conclusion. A new safety pin suture is a simple and effective procedure to control bleeding in patients with treatment-resistant, life-threatening atonic postpartum hemorrhage with the advantage of eliminating the risk of the sutures sliding off at the uterine fundus.

\section{Introduction}

Primary postpartum hemorrhage (PPH) is a major obstetric complication that can follow delivery leading to catastrophic event (hysterectomy and/or maternal death) in patients not responding to medical treatment. Even in a saved patients it may be a major cause of maternal morbidity such as renal failure and/or Sheehan's syndrome (a potentially life-threatening complication).The most common cause of $\mathrm{PPH}$ is uterine atony, which is responsible for at least 80 percent of cases [1]. Although risk factors and preventive measures are clearly known, some cases of PPH are unexpected. In developing countries, home vaginal deliveries (which still present in many areas) are poorly managed with increased risk of labor abnormalities that represent a risk factor to $\mathrm{PPH}$ and sometimes unavoidable hysterectomy. The general management of atonic $\mathrm{PPH}$ starts by conservative measures (uterine massage and uterotonics drugs) escalating to unavoidable surgical interventions (internal iliac artery ligation and hysterectomy) to control severe life-threatening bleeding [2]. Surgical uterine compression sutures, a mechanical method of compressing the uterus and closing the arterial bed to reduce bleeding, have been developed to avoid emergency hysterectomy and to preserve fertility in these patients [3-6].

\section{Patients and Method}

This is a retrospective observational study carried out at Obstetric and Gynecology Departments, Zagazig University Hospitals, Egypt on, 13 patients presented by severe atonic PPH in the period from April 2008 to December 2010. In all 13 patient, routine initial measures (uterine massage, oxytocin infusion, methergine, if not contraindicated, and misopristol) were done and when failed, compressing uterine suture was performed.

2.1. Description of the Safety Pin Suturing Technique. (1) Under general anesthesia, the patient is catheterized and placed in the Lloyd Davies position for easy access to the vagina to assess the control of bleeding.

(2) The abdomen is opened by a Pfannenstiel incision or if the patient had caesarean section following which she bled, the same incision is reopened. 


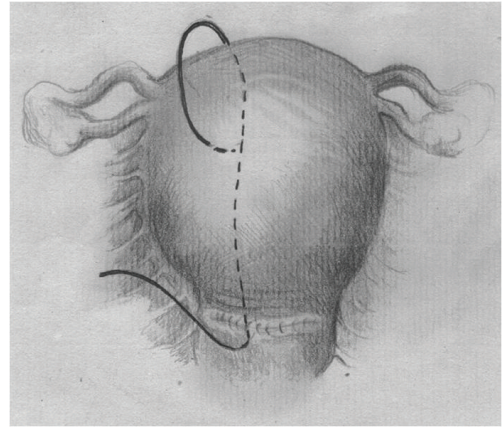

Figure 1

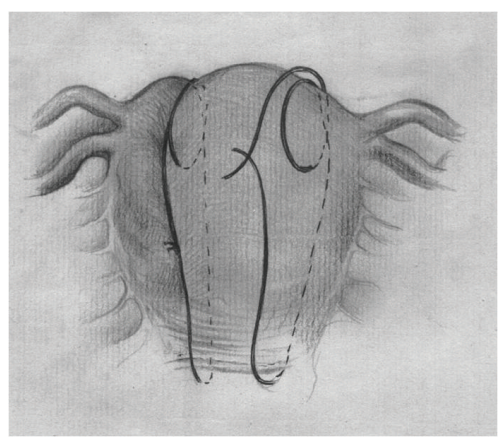

Figure 2

TABLE 1: Distribution of parity of patients.

\begin{tabular}{lcc}
\hline Parity & No. of patients & Percent \\
\hline PG & 5 & 38.5 \\
P1 & 3 & 23.1 \\
P2 & 3 & 23.1 \\
P3 & 2 & 15.3 \\
Total & 13 & 100 \\
\hline
\end{tabular}

TABLe 2: Mode of delivery.

\begin{tabular}{lcc}
\hline Mode of delivery & No. of patients & Percent \\
\hline Vaginal delivery & 3 & 23.1 \\
Elective CS & 4 & 30.8 \\
Emergency CS & 6 & 46.1 \\
Total & 13 & 100 \\
\hline
\end{tabular}

CS: Caesarean section.

(3) The uterus is exteriorised and rechecked to identify any bleeding point, if no obvious bleeding point is observed then bimanual compression is first tried to assess the potential efficacy of the compression suturing technique. The vagina is swabbed out to confirm adequate control of bleeding.

(4) If vaginal bleeding is controlled, the procedure is as follows.

Catgut 2, $70 \mathrm{~mm}$ round needle (Demetech corporation, USA) is inserted through the uterus $3 \mathrm{~cm}$ from the right lower edge of the uterine incision (or at this level if the patient was vaginally delivered) and $3 \mathrm{~cm}$ from the right lateral border without opening uterine cavity. The suture is threaded

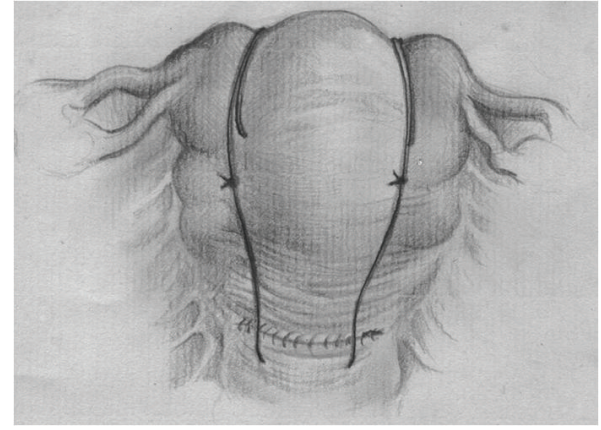

Figure 3

TABLE 3: Place of managed labor.

\begin{tabular}{lcc}
\hline Place of management & No. of patients & Percent \\
\hline Referred & 7 & 53.8 \\
Inpatient & 6 & 46.2 \\
Total & 13 & 100 \\
\hline
\end{tabular}

TABLE 4: Outcome of compression suture.

\begin{tabular}{lcc}
\hline Outcome of compression suture & No. of patients & Percent \\
\hline Successful & 12 & 92.2 \\
Failure & 1 & 7.8 \\
Total & 13 & 100 \\
\hline
\end{tabular}

through the uterine cavity to pass from the anterior to the posterior aspects then passed over the fundus, and the uterus was repunctured $4-5 \mathrm{~cm}$ below the fundus and about $4 \mathrm{~cm}$ medial to the lateral border (Figure 1). The needle was then passed from the anterior to the posterior fundal region through the uterine cavity. The suture was again passed from the posterior aspect over the fundus to reach the anterior fundal region (Figure 2). The two ends of the thread were tied on the anterior wall as tightly as possible while an assistant applied bimanual compression. During such compression the vagina is checked to insure that the bleeding is controlled. The procedure was then repeated on the left (Figure 3 ). Care was taken not to damage the bowel and the bladder.

The patient's age, parity, gestation of pregnancy, presenting diagnosis, mode of delivery, and volume replacement were recorded (see Table 5). The age of patients was between 21 and 33 years (mean 27 years). Parity ranged from 0 to 3 as showed in Table 1 , and the gestational age at which the procedure was performed ranged from 34 to 41 weeks (mean 38 weeks).

\section{Results}

Severe atonic PPH occurred in thirteen cases with risk factors for atony. The majority of patients $(61.5 \%)$ were multiparas (see Table 1 ). Seven cases $(53.8 \%)$ were referred to our units poorly managed, and urgent delivery was needed. The other six cases $(46.2 \%)$ were admitted for antenatal care and managed in our unit (see Table 3 ). Caesarean section was 
TABLE 5: Summary of characters of patients with severe atonic PPH treated by the use of safety pin uterine compression suture.

\begin{tabular}{|c|c|c|c|c|c|}
\hline Age (yrs) & Parity & Gestation (wks) & Presenting diagnosis & Mode of delivery & Volume replacement \\
\hline 24 & PG & $39 / 40$ & Prolonged labor & Emergency LSCS & $\begin{array}{l}4 \text { blood units } \\
2 \text { FFP units }\end{array}$ \\
\hline 28 & $\mathrm{P} 1$ & $36 / 40$ & Accidental hemorrhage & Vaginal delivery & $\begin{array}{l}8 \text { blood units } \\
4 \text { FFP units }\end{array}$ \\
\hline 21 & PG & $37 / 40$ & Severe PET & Emergency LSCS & 4 blood units \\
\hline 23 & PG & $34 / 40$ & $\begin{array}{c}\text { Severe PET, } \\
\text { HEELP syndrome }\end{array}$ & Emergency LSCS & $\begin{array}{l}6 \text { blood units } \\
3 \text { FFP units }\end{array}$ \\
\hline 28 & PG & $38 / 40$ & Twins pregnancy & Elective LSCS & $\begin{array}{l}4 \text { blood units } \\
2 \text { FFP units }\end{array}$ \\
\hline 27 & PG & $40 / 40$ & Obstructed labor & Emergency LSCS & $\begin{array}{l}7 \text { blood units } \\
2 \text { FFP units }\end{array}$ \\
\hline 33 & P3 & $39 / 40$ & Prolonged labor & Vaginal delivery & $\begin{array}{l}10 \text { blood units } \\
4 \text { FFP units }\end{array}$ \\
\hline 29 & $\mathrm{P} 2$ & $39 / 40$ & PGD, over sized baby & Elective LSCS & $\begin{array}{l}5 \text { blood units } \\
2 \text { FFP units }\end{array}$ \\
\hline 27 & $\mathrm{P} 2$ & $37 / 40$ & $\begin{array}{c}\text { Hydrocephalus, }(\mathrm{PBD}=122 \mathrm{~mm}) \\
\text { polyhydramnios }\end{array}$ & Elective LSCS & $\begin{array}{l}5 \text { blood units } \\
2 \text { FFP units }\end{array}$ \\
\hline 33 & P3 & $38 / 40$ & $\begin{array}{l}\text { Accidental hemorrhage, } \\
\text { (DIC) }\end{array}$ & Vaginal delivery & $\begin{array}{l}12 \text { blood units } \\
6 \text { FFP units }\end{array}$ \\
\hline 24 & $\mathrm{P} 1$ & $41 / 40$ & Obstructed labor & Emergency LSCS & $\begin{array}{l}5 \text { blood units } \\
2 \text { units FFP }\end{array}$ \\
\hline 29 & P2 & $38 / 40$ & Prolonged labor & Emergency LSCS & $\begin{array}{l}7 \text { blood units } \\
3 \text { FFP units }\end{array}$ \\
\hline 23 & P1 & $36 / 40$ & Triplet pregnancy (ICSI) & Elective LSCS & $\begin{array}{l}5 \text { blood units } \\
2 \text { FFP units }\end{array}$ \\
\hline
\end{tabular}

LSCS: lower segment caesarean section. FFP: fresh frozen plasma. DIC: disseminated intravascular coagulation. PGD: pregestational diabetes. ICSI: intracytoplasmic sperm inoculation.

done in ten cases $(76.9 \%)$ and three cases $(23.1 \%)$ delivered vaginally (as shown in Table 2). Compression suture was performed for major primary $\mathrm{PPH}$ caused by uterine atony in 10 cases after caesarean section and 3 cases after vaginal delivery. The uterine compression suture technique was sufficient to stop bleeding immediately in $92.2 \%$ of the women. In one woman $(7.8 \%)$, the procedure failed, and hysterectomy was done (see Table 4). The total blood loss ranged from 2,000 to $6,000 \mathrm{~mL}$ (mean $4,000 \mathrm{~mL}$ ). The hospital stay ranged from 4 to 7 days (mean 5 days). All the patients made a good postoperative recovery. None of the women developed complications related to the procedure. Only one patient had a secondary wound infection and was successfully managed. In all cases, followup (gynecological examination vaginal and abdominal ultrasound) done six weeks after delivery was normal. Hysteroscopic evaluation of uterine cavity for all successfully managed 12 cases was performed three months after the procedure and showed normal uterine cavities.

\section{Discussion}

$\mathrm{PPH}$ is a serious obstetric problem that threatens patient life. It is still one of the leading causes of maternal secondary and morbidity. Uterine atony is the most common cause of primary postpartum hemorrhage. Early diagnosis and management of risk factors greatly decrease its incidence [7].
In general, the management of atonic $\mathrm{PPH}$ includes patient resuscitations and simple medical measures escalating to invasive surgical procedures depending on patient response and hemodynamic state. Bilateral hypogastric artery ligation (BHAL) decreases bleeding by about $70 \%$. However, it requires experience and surgical skill that is not available for many surgeons, and it is not without substantial risk of failure [8]. Major postpartum blood loss in hemodynamically unstable patients is more likely to need hysterectomy that can be one of the most dangerous procedures. Its complications include the permanent loss of fertility together with physical and psychological sequelae [9]. In 1997, a surgical technique for compression and apposition between the anterior and posterior walls of the uterus was described by Lynch in five women with postpartum hemorrhage [3]. Since its introduction into practice, the B-Lynch compression suture technique has been applied successfully worldwide and gained popularity [10], and variations on this compression technique have been described by other authors [4-6]. In our unit, a limited number of surgeons are familiar with internal artery ligation. So we try to practice compression suture technique for drug resistant-atonic PPH. B-Lynch suture was applied after the test of potential efficacy. However, we faced some difficulty due to slipping off suture at the lateral upper margins. In order to overcome this problem, we try to modify B-Lynch suture by firm transfixation of suture at uterine 
fundus. This was achieved by an additional firm puncture below the uterine fundus without obvious additional bleeding and tying the two ends anteriorly. In our study we faced 13 patients presented by severe atonic $\mathrm{PPH}$. Initial general management was done and when failed, safety pin suture was applied after the test of potential efficacy (a simple bimanual compression after exteriorising the uterus) and was very effective in controlling bleeding with no need of additional surgical procedure in 12 cases $(92.2 \%)$. Only in one case, the patient was referred to our unit presented by severe accidental hemorrhage and intrauterine fetal death. The patient was shocked with blood pressure 70/30 mmhg and feeble, rapid pulse $(120 \mathrm{~b} / \mathrm{min}$.). Spontaneous vaginal delivery was achieved within 15 minutes with antishock measures done. Severe atonic PPH occurred with no response to massage and uterotonics drugs. Laparotomy was done with failure of safety pin suture to control bleeding. Hysterectomy was done, but unfortunately, DIC WAS superimposed, and the patient died after 4 hours. It is important to note that such suturing techniques may not achieve adequate control of bleeding particularly when there is coagulopathy and diffuse bleeding from an atonic uterus, and delay in effecting surgical technique may further compromise the patient. We have found that safety pin uterine compression suture is simple, effective, easy to learn, and can be easily performed during caesarean section as in vaginal delivery without risk of internal iliac artery ligation or hysterectomy complications. The time needed to complete the procedure decreased each time to be not more than 10 minutes by the end of the study and can be undertaken without opening the uterine cavity, which distinguishes it from the original B-Lynch suture with the advantage of decreasing the duration of anesthesia and blood loss. Also, many surgeons in our unit became familiar with the technique which helped in saving the life and future fertility of many patients. Complications of infections and intrauterine synechiae have been described after compression techniques [11]. In our series, none of the women developed complications related to the procedure, and follow-up diagnostic hysteroscopy done three month later for all successfully managed 12 cases showed clear uter-ine cavity with nice view of uterine ostia. Only in one case, gaped wound infection was successfully cleaned and repaired with secondary suture.

\section{Conclusion}

Safety pin uterine compression suture is a simple, safe, highly effective, and life-saving conservative procedure to control atonic postpartum hemorrhage with the advantage of preserving future fertility. All obstetric units which should have clear guidelines to deal with this emergency and techniques that allow preservation of the uterus should be applied when possible.

\section{References}

[1] Obstetric Hemorrhage Williams Obstetrics, McGraw-Hill Medical Publishing Division, New York, NY, USA, 22nd edition, 2005.
[2] G. S. Condous and S. Arulkumaran, "Medical and conservative surgical management of postpartum hemorrhage," Journal of Obstetrics and Gynaecology, vol. 25, no. 11, pp. 931-936, 2003.

[3] C. B-Lynch, A. Coker, A. H. Lawal, J. Abu, and M. J. Cowen, "The B-Lynch surgical technique for the control of massive postpartum hemorrhage: an alternative to hysterectomy? Five cases reported," British Journal of Obstetrics and Gynaecology, vol. 104, no. 3, pp. 372-375, 1997.

[4] R. G. Hayman, S. Arulkumaran, and P. J. Steer, "Uterine compression sutures: surgical management of postpartum hemorrhage," Obstetrics \& Gynecology, vol. 99, no. 3, pp. 502-506, 2002.

[5] J. M. Cho, H. S. Jun, and C. N. Lee, "Haemostatic suturing technique for uterine bleeding during cesarean delivery," $\mathrm{Ob}$ stetrics \& Gynecology, vol. 96, no. 1, pp. 129-131, 2000.

[6] J. Ouahba, M. Piketty, C. Huel et al., "Uterine compression sutures for postpartum bleeding with uterine atony," An International Journal of Obstetrics \& Gynaecology, vol. 114, no. 5, pp. 619-622, 2007.

[7] G. Lewis and The Confidential Inquiry into Maternal and Child Health (CEMACH), Eds., Saving Mothers' Lives: Reviewing Maternal Deaths to Make Motherhood Safer-2003-2005. The 7th Report on Confidential Enquiries into Maternal Deaths in the United Kingdom, CEMACH, London, UK, 2007.

[8] E. Paraskevaides, L. Noelke, and M. Afrasiabi, "Internal iliac artery ligation (IIAL) in obstetrics and gynaecology," European Journal of Obstetrics Gynecology and Reproductive Biology, vol. 52, no. 1, pp. 73-75, 1993.

[9] S. Zeteroglu, Y. Ustun, Y. Engin-Ustun, G. Sahin, and M. Kamaci, "Peripartum hysterectomy in a teaching hospital in the eastern region of Turkey," European Journal of Obstetrics Gynecology and Reproductive Biology, vol. 120, no. 1, pp. 5762, 2005.

[10] E. El-Hamamy and C. B-Lynch, "A worldwide review of the uses of the uterine compression suture techniques as alternative to hysterectomy in the management of severe post-partum haemorrhage," Journal of Obstetrics and Gynaecology, vol. 25, no. 2, pp. 143-149, 2005.

[11] H.-H. Wu and G.-P. Yeh, "Uterine cavity synechiae after hemostatic square suturing technique," Obstetrics \& Gynecology, vol. 105, no. 5, pp. 1176-1178, 2005. 


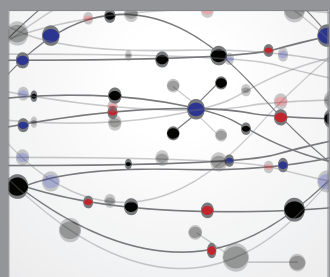

The Scientific World Journal
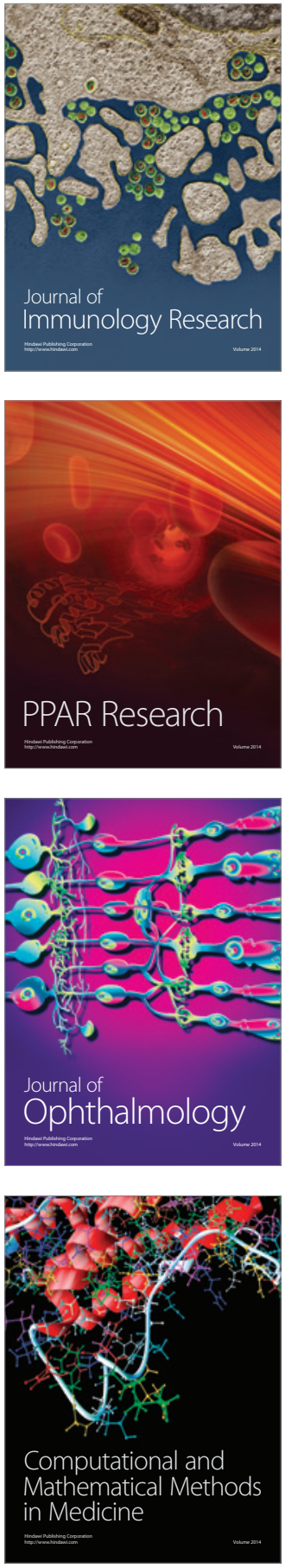

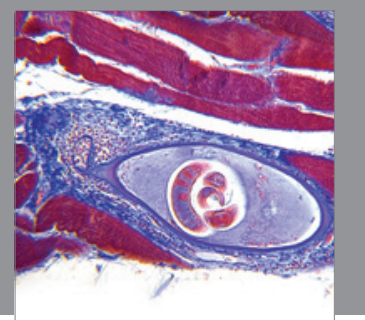

Gastroenterology

Research and Practice
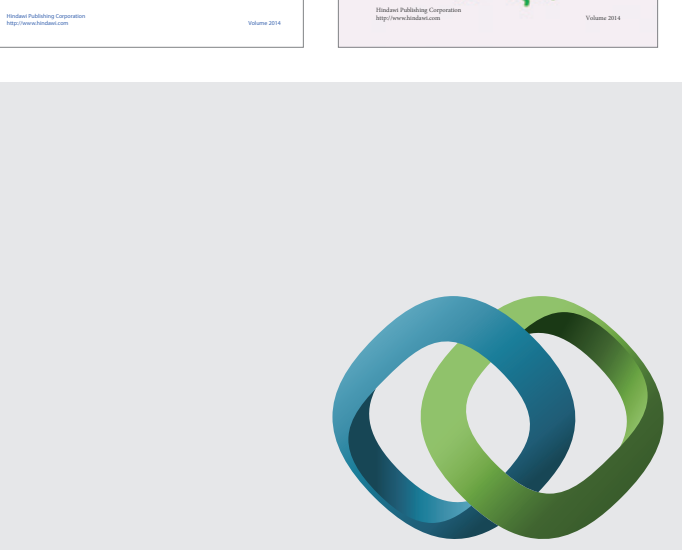

\section{Hindawi}

Submit your manuscripts at

http://www.hindawi.com
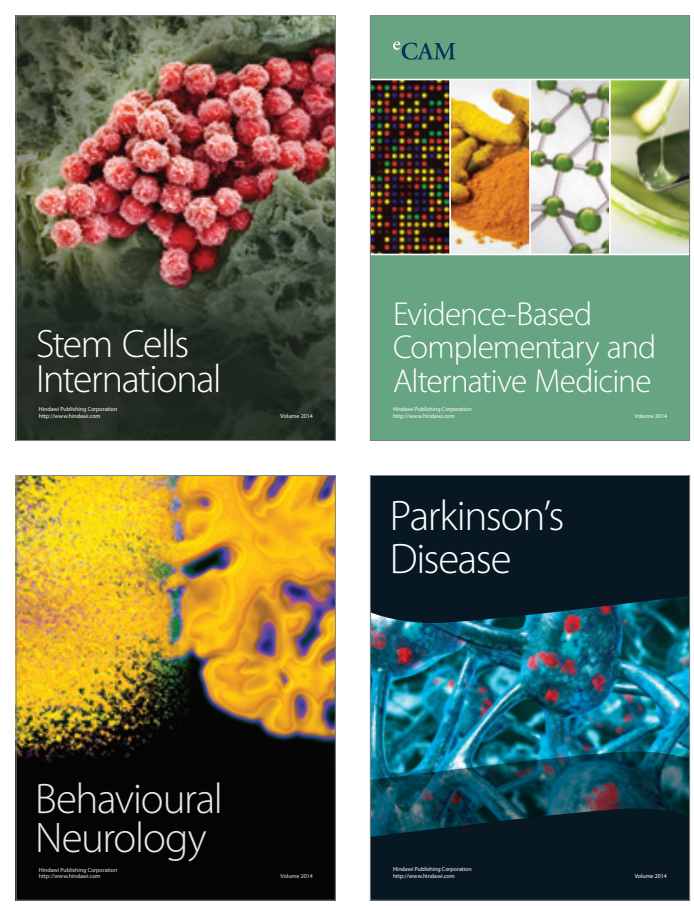

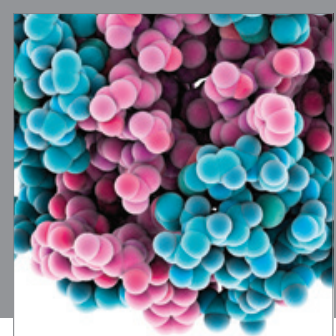

Journal of
Diabetes Research

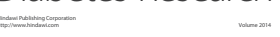

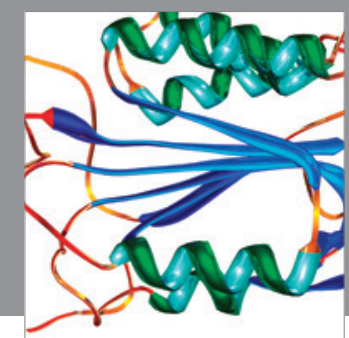

Disease Markers
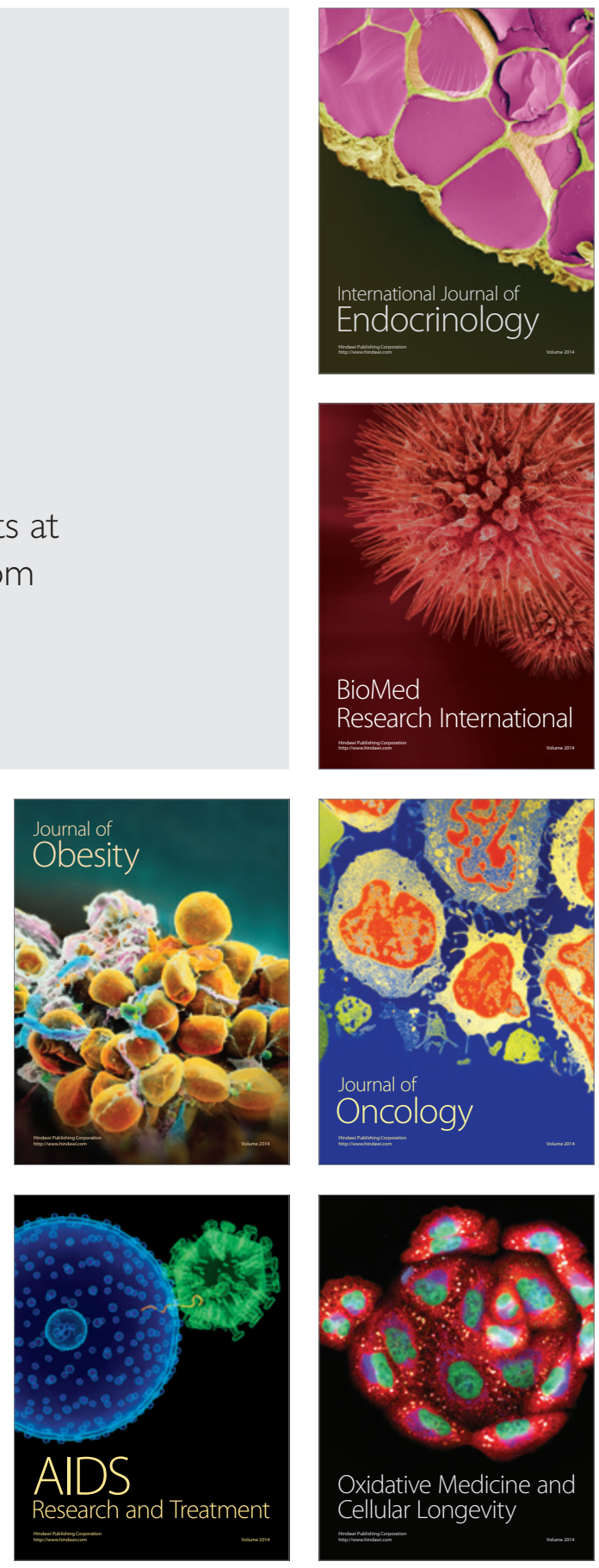